\title{
Fim de uma ordem: natureza, lei divina, feminismo
}

\author{
End of an order: nature, divine law, feminism
}

\author{
Brenda Maribel Carranza* \\ Maria José Fontelas Rosado-Nunes**
}

\begin{abstract}
Resumo
Este texto orienta-se pela hipótese de que o magistério da Igreja Católica e os estudos de gênero operam com pressupostos epistemológicos distintos ao formularem a noção de natureza humana e sua força analítica transcende as especulações acadêmicas e os âmbitos teológicos. Para a argumentação dessa proposta analisam-se algumas abordagens sobre a compreensão da natureza nos estudos de gênero e nos documentos pontíficios. Constata-se que longe de ser apenas um embate epistemológico o que emerge é a relevância política da categoria de gênero e sua intrínseca relação com o feminismo. Ainda, discute-se como deslizam os léxicos científicos e doutrinais para a sociedade onde há um confronto político entre dois movimentos: o feminismo e as campanhas antigênero, essas últimas com dimensões transnacionais que ultrapassam os grupos conservadores do cristianismo que as lideram.
\end{abstract}

Palavras-chave: lei natural; natureza humana; estudos de gênero; feminismo; campanha antigênero.

\begin{abstract}
This text is guided by the hypothesis that the Catholic Church teaching and gender studies operate on distinct epistemological assumptions in formulating the human nature notion, and its analytical force transcends academic speculation and theological realms. This argument is based on the analysis of some some approaches to the comprehension of nature in gender studies and pontifical documents. Far from being merely an epistemological clash, the political relevance of the gender category and its intrinsic relationship with feminism emerges. Moreover, we discuss how scientific and doctrinal lexicons slide into a society where there is a political confrontation between two movements: feminism and anti-gender campaigns, the latter with transnational dimensions that surpass the conservative groups of Christianity that lead them.
\end{abstract}

Keywords: natural law; human nature; gender studies; feminism; anti-gender campaign.

\footnotetext{
Artigo submetido em 17 de junho de 2019 e aprovado em 26 de agosto de 2019.

* Doutora em Ciências Sociais pela UNICAMP. Professora da PUC-Campinas. País de origem: Guatemala. E-mail: brenda_poveda@terra.com.br

** Doutora em Ciências Sociais pela École des Hautes Études, Paris. Professora da PUC-SP. País de origem: Brasil. E-mail: mjrosado@uol.com.br
} 


\section{Introdução: olhares singelos à complexa vida de Adão e Eva}

Há mais de cem anos Henry Festing Jones publicava do polifacético artista britânico Samuel Butler (1835-1902), seus registros autobiográficos. Um tributo amigo ao poeta iconoclasta, engajado em polêmicos debates na era vitoriana, e autor da novela Erewhon, famoso best seller à época que evoca a estada de Butler na Nova Zelândia. Nos seus written sketches Butler (1917), captura intuitivamente o seguinte diálogo: "Duas crianças olham uma representação de Adão e Eva numa Bíblia ilustrada. 'Qual destas personagens é Adão e qual é Eva?', pergunta uma delas. 'Não sei', responde a outra; 'mas eu poderia lhe dizer se estivessem vestidas.".1 (BUTLER, 1917, p. 243).

Na interpretação de Butler, as crianças olham uma representação idealizada, na mentalidade judeo-cristã, de um homem e uma mulher, se perguntam quem é quem e evocam a vestimenta como marcadores de distinção sexual que poderiam ajudar na identificação das personagens. Uma singela imagem: Eva e Adão, seres, pessoas, personagens que trazem criptografadas interpretações justapostas do que é uma suposta natureza humana. Interpretação, muitas vezes essencialista, que cristaliza o resultado de processos históricos, culturais e políticos nos quais foi sendo tecida a trama corpórea dos seres humanos, sua subjetividade e subjetivação. Tecidas, também, as formas discursivas que classificam seus corpos, definem sua identidade e determinam o papel sexual a ser desempenhado na sociedade. Dito de outra forma, uma estrutura que emoldura uma dimensão da vida cotidiana sintetizada na palavra: gênero (CONELL, 2016, p. 17).

Encapsulado em complexas compreensões, o gênero transborda a materialidade biológica dos corpos, na sua anatomia, hormônios, cromossomos. Ou em compreensões que enfatizam as dimensões científicas do sexo para logo as reduzir a funções reprodutivas que passam a ser enaltecidas social e religiosamente como a razão e o sentido único de vida das mulheres e dos homens, mesmo que o

\footnotetext{
${ }^{1}$ Tradução livre de: “A litle boy and a litle girl were looking at a picture of adam and Eve. 'Which is Adam and which is Eve?' said one. 'I do not know', said the other, 'but I could tell if the had theri clothes on'."
} 
preço a pagar implique negar direitos. Sentido religioso, virtude social e função reprodutiva fusionadas correm para inexoráveis imperativos de maternidade, paternidade, heteronormatividade e seus correlatos.

Sem dúvida que, nesse diálogo singelo das crianças, e seus desdobramentos analíticos, podemos capturar alguns dos elementos que compõem o marco de discussão neste texto. O que provoca a pensar, o que talvez nunca se teria pensado. Sobre os efeitos desse exercício Foucault (1984) indaga: "qual seria o valor da paixão pelo saber, se ela resultasse apenas num certo conhecimento... e não, de algum modo, num desregramento de si mesmo por parte do conhecedor?" (FOUCAULT, 1984, p. 11).

Esta reflexão se propõe revisitar aquilo que seria desregrar o pensamento em torno dos pressupostos epistemológicos da noção de natureza humana que subjazem tanto no corpus dos estudos de gênero quanto na tradicional doutrina sobre lei natural da Igreja Católica.

A hipótese que orienta esta reflexão é que a força analítica desses pressupostos transcendeu a academia e a Igreja, no momento em que a categoria gênero foi apropriada pelos movimentos sociais. Mas, quando os estudos de gênero são nomeados pela Igreja de teoria de gênero e/ou de ideologia de gênero ${ }^{2}$ ganham maior existência social, porém sofrem desqualificação analítica, são rejeitados socialmente e tratados como inimigos da vida pública.

Mais ainda, nesse embate entre a doutrina e os estudos de gênero, seus pressupostos deslizam para a vida pública, então presencia-se na sociedade dois movimentos políticos com sinais distintos: o feminismo e as campanhas antigênero, lideradas, principalmente, por grupos cristãos conservadores.

\footnotetext{
${ }^{2}$ Éric Fassin (2016, p. 176) propõe distinguir entre estudos de gênero e teoria de gênero, sendo essa última atribuída à terminologia com que o Papa Bento XVI designa o conjunto de questões sobre gênero. Já ideologia de gênero, para o autor, seria uma estratégia discursiva contra o gênero, mais utilizada pelo Papa Francisco.
} 
Para dar passo à argumentação que sustenta essa tese inicia-se por destrinchar , a partir de uma perspectiva hitórica e interdisciplinar, a noção de natureza que mostrou sua complexidade à medida que foi sendo "desregrada" pelos estudos de gênero. Na sequência abordam-se o regimem de verdades contidos na doutrina do magistério católico, para logo analisar como um léxico epistemológico sobre a natureza adquire conotações políticas, desaguando nas campanhas antigênero.

\section{Questionar processos para reimaginar conceitos}

É possível pensar na teoria como algo que se desenvolve no âmbito acadêmico? Como apenas uma especialização? Com essas perguntas, Judith Butler (2015, p. 1) inicia uma palestra em Buenos Aires sobre a materialidade corpórea e sua desconstrução discursiva.3 A autora começa por discorrer sobre a importância de pressupostos teóricos pois, segundo ela, não existe posição política que não faça uso deles. Opiniões teóricas 4 decorrem de processos históricos que, muitas vezes, são marcados por uma tensão continua de como pensar em contextos políticos determinados. Da mesma maneira, definições abreviam opiniões teóricas, condensam processos históricos e nomeiam fenômenos. Ao utilizarmos categorias que orientem argumentos lança-se mão das consequências práticas e do impacto político que esses supostos analíticos trazem (BUTLER, 2015, p. 3).

É um desafio imaginar a valia dessa operação discursiva quando se trata de argumentações teóricas de como pensar gênero, sexo e corpo, categorias estabelecidas há muito tempo e carregadas de camadas e mais camadas de interpretação. Mas, para que insistir em repensar essas categorias tão estabelecidas? Butler (2015, p. 3) sugere: "é para ter uma intervenção no mundo [...], pois o mundo não pode mudar sem ter uma intervenção crítica”. Postura que

\footnotetext{
${ }^{3}$ Realizada em Buenos Aires no 16 de setembro de 2015, Universidade Tres de Febrero. A transcrição, na íntegra, para o espanhol é de Maria Isabel Burgos Fonseca.

${ }^{4} \mathrm{O}$ termo opiniões teóricas é utilizado pela autora da transcrição da palestra realizada em Buenos Aires. Na revista brasileira Sapere Aude, encontra-se traduzido o prólogo do livro Corpos que importam (Bodies That Matter): Butler (2015b). Essa tradução não inclui a discussão sobre os pressupostos políticos implícitos na produção do conhecimento científico. Embora com o mesmo título, compreendemos que são documentos de natureza distinta. Por isso, optamos por adotar a tradução espanhola da palestra de Butler, na qual o termo opinião teórica é ventilado.
} 
obedece à função social que o corpo teórico do gênero tem ao informar ações políticas na vida cotidiana. Por isso, neste texto interessa lastrear como o gênero questiona a categoria natureza humana, perante a tradição cristã em geral, e no catolicismo em particular, e sinalizar como o movimento feminista transforma em ação política esse questionamento tido como uma ordem estabelecida.

Embora no passado as ciências biomédicas e as ciências sociais dividissem seus campos em estudos dos corpos e estudos dos processos sociais, de vez em quando, aparecia certa rixa sobre qual era mais importante: "natureza" versus cultura. A determinação biológica era tida como fundamental e o paradigma biomédico aquele que reinava, quando de corpos se tratava, sobretudo ao serem pensados os direitos, as políticas públicas e sanitárias (CONELL, 2016, p. 46).

No do final da década de 60 e no correr dos anos 70 do século XX discussões e pesquisas em torno do que seja "a natureza" e, mais especificamente, uma "natureza humana”, ganham corpo. O que parecia definitivamente resolvido, marcado pela biologia e pela anatomia humana, passa a ser objeto de interrogação e de dúvida. Seria a biologia, com sua taxonomia encarregada de categorizar os fatos biológicos, o único marcador a classificar os seres humanos? E mais, não seriam as próprias compreensões da biologia, seus achados e seus cientistas também construções culturais devedoras da historicidade, do tempo e do espaço em que foram criadas? Indagar sobre o que poderia ser compreendido como uma “natureza" própria aos seres humanos e o que os definiria como feminino e como masculino, homem e mulher renderam inúmeros trabalhos de estudiosas e estudiosos á época (ROSADO-NUNES, 2018, p. 13).

Repensar definições é interrogar processos históricos. Essa foi a tarefa dos estudiosos e estudiosas que se debruçaram sobre as categorias que por séculos haviam relegado as mulheres á "natureza", alçando os homens à condição de criadores da cultura. Na sequência, a casa seria o espaço privado próprio às mulheres e a rua, o espaço público, domínio dos homens. 
A convencional classificação binária da humanidade seria colocada na mira de suspeita. Seria mesmo binária? A corporeidade seria reduzida à genitália, tendo os órgãos genitais como os descritores que definiram uma única forma de masculinidade e uma única forma de feminilidade, atribuindo a primeira aos homens e segunda às mulheres? Tais descritores que definiriam papéis sexuais e sociais, espaços domésticos e públicos, seriam realmente naturais?

Aqui será formulado o primeiro pressuposto dos estudos de gênero. Neles, a compreensão do sexo não seria mais tido como um dado natural, mas como criação social, portanto, histórica. Ou seja, as ideias e os conceitos que se tem sobre os próprios corpos obedecem a certos condicionantes sócio-culturais. Decorre um segundo pressuposto: os discursos sobre a funcionalidade e finalidade do sexo serão entendidos como constructos que operam certa compreensão sobre ele e, enquanto dispositivos discursivos, são produzidos no jogo de poder.

Com isso, a predominância de determinados discursos sobre outros discursos encontra-se diretamente atrelada à capacidade de dominação que certos grupos detêm para impor sua visão. Consequentemente, passa-se, de um lado, da seara da linguagem prescritiva, que estabelece a ordem sexual, delimita as fronteiras do que é certo ou errado em matéria sexual e naturaliza assimetrias nas relações, para, do outro lado, a seara política onde se negocia a imposição de determinados discursos, sejam científicos e/ou religiosos (VAGGIONE, 2012, p. 1314).

Nesse ínterim, um debate ardoroso entre as ciências biológicas e sociais será travado nos seguintes termos. A biologia precisa inventar um objeto fixo, um corpo a-histórico, sexuado, estranho ao domínio da significação, isso permite á biologia afirmar-se como ciência e se constituir como disciplina científica (LAQUEUR, 1990). Por sua vez, tal pressuposto desse objeto como fixo permite sua coisificação e reificação, ao que a crítica feminista reage alertando sobre a rigidez dessa noção de corpo (HARDING, 1993; HARAWAY, 1995). 
No entanto, existem outras posturas como a da bióloga americana Anne Fausto-Sterling que foca suas pesquisa na complexidade do sexo de um corpo e a sutilidade de suas diferenças. Para a autora, o mundo ocidental, europeu e americano, tende a entender, em grande parte, o funcionamento do mundo de maneira dual e antitética, conceitos, objetos ou sistemas de crenças de maneira oposta. Isso se estende às diferenças sexuais, que para ela, são por demais sofisticadas para serem encapsuladas em duas palavras: homem ou mulher.

Por isso, a nomeação do sexo é uma decisão social para a qual o conhecimento científico auxilia, mas são as crenças sobre o gênero e não a ciência que definem o sexo. Ainda, ela afirma que "[são] nossas crenças sobre o gênero que também afetam o tipo de conhecimento que os cientistas produzem sobre o sexo" (FAUSTO-STERLING, 2002, p. 15). A autora reconhece que o artigo da cientista social Mary MacIntosh (1968), tornou-se "a pedra de toque que levou os estudiosos a considerarem a sexualidade um fenômeno histórico" diferentemente dos filósofos para quem a caracterização da sexualidade humana é descrita em termos de "tipos naturais" (FAUSTO-STERLING, 2002, p. 37).

Tipos naturais que vêm ao encontro do senso comum para o qual as condutas ou as ditas virtudes femininas (fragilidade) e masculinas (virilidade) são evidentes de uma inscrição natural nos próprios corpos, colocando-os na esfera doméstica e pública, respectivamente. Da mesma forma, para a antropologia, estudiosa da diversidade cultural das sociedades, a dimensão biológica da espécie humana não é o único fator explicativo da sua sexualidade. Há sim outros fatores como o da " capacitação cultural enquanto elemento essencial da sobrevivência. “[pois] É a cultura que humaniza a espécie, e o faz em sentidos muito diferentes” (HEILBORN, 2002, p. 4). Nessa mesma linha, o sociólogo francês Alain Touraine (2010) insiste no elemento contrastivo em que a tal: "natureza da mulher é construída pela vontade social de confiar o monopólio das relações legítimas entre seres sexuados à relação heterossexual dominada pelo homem em que atribui um papel á mulher, um papel de reprodução organizada e controlada pelo homem” (TOURAINE, 2010, p. 32). 
No âmbito da psicologia pesquisas sobre as diferenças de sexo "não conseguiram encontrar qualquer evidência em larga escala, ou um universal de diferenças entre mulheres e homens" (WHOODHEAD, 2013, p. 58), o que atesta, de acordo com a autora, que a percepção do gênero como um ou como múltiplo, depende dos contextos culturais. Ainda assim, a psicologia como a medicina, e algumas vertentes da biologia, como se disse acima, necessitam de corpos com identidades sexuais bem definidas (GARDEY; LÖWY, 2000, p. 25). Talvez porque “o que não se consegue classificar, torna-se um perigo em qualquer cultura”. 5

Apesar de nas ciências não se ter as evidências ou universais sobre essas diferenças, nas primeiras décadas do século XX, o conceito de heterossexualidade incorporou-se como característica permanente da paisagem sexual e como consenso de normalidade. Posteriormente, comunidades lésbicas e gays reivindicaram sua condição sexual como plenamente normal. A essas vozes, somaram-se pessoas transexuais e intersexuais que contestam o modelo de dois sexos e reclamam para si a normalidade como condição da sua sexualidade (FAUSTO-STERLING, 2002, p. 48). Éric Fassin (2016, p. 183), comentando o trabalho de Fausto-Sterling, esclarece que o epicentro da questão colocada pelos movimentos interssexuais é a construção arbitrária de uma divisão binária do sexo; portanto, para o autor, coompreende-se porque a bióloga feminista enfatiza que as razões para manter esse sistema dual, no lugar de outro qualquer, são tudo, menos biológicas.

Avançada a discussão, a desestabilização da hegemonia de uma ordem sexual baseada no regimem binário da heterossexualidade só é possível com reconhecimento de normalidade dessas sexualidades, mas é o impacto cultural e político dos movimentos feministas e pela diversidade sexual que consegue colocar, essa desestabilização, na pauta social (GARDEY; LÖWY, 2000, p. 26). A intervenção nos corpos sexuados, como no caso de pessoas transsexuais que reivindicam por meio de cirugias a condição de normalidede de sua sexualidade,

${ }^{5}$ Intervenção do professor Fernando Torres Londoño em banca de doutorado, na PUC-SP, em 2017. 
será o Estado que decide. Ele define quem é homem e quem é mulher, as condições de como se tornar homem ou mulher, ainda é o Estado que resolve juridicamente se a pessoa deve manter a categoria de reconhecimento binário (homem ou mulher) ou se pode se encaixar na categoria outro (a que a classifique sexualmente). Situação que permite adentrar-se ao que Vaggione (2012, p. 16) denomina de complexo entramado de regras e regulações que regem a ordem binária que, para o autor, está longe de colar a sexualidade à "natureza”, antes está mais perto de ser o núcleo central de uma ordem social hierárquica que distribui de maneira desigual direitos e privilégios.

Por isso, as compreensões abertas que reconhecem múltiplas formas de realização humana não são as únicas que encontram resistência na noção de heterossexualidade enquanto parâmetro de normalidade e na definição binária dos seres humanos. Mas, também, os entramados regulatórios que se defrontam com uma nova compreensão do sexo em que este não é apenas um fato biológico, simplesmente um dado da natureza, mas é percebido como construção complexa de uma plasticidade enorme nas fronteiras entre os gêneros.

Interessa destacar nesta reflexão o ponto cruzial da ruptura com o naturalismo como uma concepção normalizadora e determinista, definida a partir de dados da anatomia e da biologia sobre o que seja a natureza humana. Natureza humana assentada num modelo binário que, por sua vez, estrutura uma ordem sexual que impõe um único modo de sexualidade humana e o legitima como o normal, o certo.

$\mathrm{Na}$ contramão, os pressupostos do gênero levam a refletir na fluidez das identificações em termos de gênero, de sexualidade e das definições identitárias do "ser homem" e do "ser mulher", sedimentadas como "verdade segura” (DUQUE, 2017, p. 15-16). São esses os pressupostos epistemológicos dos estudos de gênero que permitem a compreensão de que há possibilidades múltiplas de realização dos seres humanos, quanto à sua sexualidade e ao que querem que os defina - ou não defina! 
Porém, nem a sociedade nem a ciência suportam a ambiguidade e a ausência de definições claras e fixas. Ainda mais as religiões que se propõem a dizer a verdade, e uma única verdade, a respeito não apenas de divindades e suas leis, mas da humanidade, sua natureza e sua sexualidade. São os pressupostos desse regime de verdades, presente na noção de lei natural, proposta pela doutrina católica e subjacente nas campanhas antigênero, que ocuparão as próximas páginas.

\section{A natureza como ordenamento divino}

No início do século XX, o Papa Leão XIII, na sua encíclica Libertas praestantissimum, sobre a liberdade humana, afirmava: "a lei natural se acha escrita e gravada na alma de todos e de cada um dos homens, porque ela é a razão humana, ordenando fazer o bem e proibindo pecar”. Também reconhecia que essa “prescrição da razão não poderia ter força de lei se não fosse a voz e o intérprete de uma razão mais alta, à qual nosso espírito e nossa liberdade devem submeter-se” (IGREJA CATÓLICA, 1946, n. 184). O Papa invoca a lei natural para legitimar sua autoridade num conturbado fim do século XIX, defender, entre outros, a propriedade privada perante o socialismo, o direito trabalhista a um salário digno, estabelecer limites entre autoridade civil e ameaças às leis naturais e divinas (COMISIÓN TEOLÓGICA INTERNACIONAL, 2006-2008, n. 34-45) ${ }^{6}$.

Muitas décadas depois, num final de século XX marcado por ambientes plurais e democráticos, o catecismo da Igreja Católica (2011) atualiza os princípios dessa lei, enunciando-a como a " 'lei divina e natural' que mostra ao homem o caminho a seguir para praticar o bem e atingir seu fim. [ela]... enuncia os preceitos primeiros e essenciais que regem a vida moral” (IGREJA CATÓLICA, 2011, p. 517). Valores que tem seu fundamento no bem moral que consiste em fazer o bem e evitar o mal, também expresso na regra de ouro: não faça ao outro o que não quer para você. Regra que terá seu alcance para toda a humanidade.

\footnotetext{
${ }^{6}$ A Comissão Teológica Internacional, convocada pelo Vaticano, foi integrada por 9 teólogos, professores e clérigos e 1 professora, para estudar o tema: A busca de uma ética universal: nova perspectiva sobre a lei natural. Os trabalhos da Comissão duraram três anos (de out. 2006 a dez. 2008), sendo entregue o documento final ao cardeal William J., quem autorizou sua publicação.
} 
$\mathrm{Na}$ moral cristã três inclinações serão reconhecidas como naturais: conservar e proteger a vida, reproduzir-se para perpetuar a espécie, conhecer a Deus e viver em sociedade. Para que isso aconteça devem ser providenciadas as condições que garantam a qualidade biológica (integridade do corpo, alimentação, vestuário, teto, trabalho), o prolongamento da própria espécie (procriação natural e heterossexual) e o desenvolvimento harmônico e responsável do ser. É assim que um bem moral será garantido, enquanto um valor a ser alcançado, uma obrigação a cumprir e um direito a fazer valer. São, portanto, os valores morais que constituem a lei natural e essa constitui a base da ordem social e política que não requer adesão de fé, mas da razão. Quando compartilhados com o resto dos seres humanos, esses preceitos constituem um mandato prático que se concretizarão na vida (COMISIÓN TEOLÓGICA INTERNACIONAL, 2006-2008, n. 37, n. 99).

No entanto, para os crentes que compartilham sua fé, a natureza humana, como criação de Deus, é a fundamentação de preceitos que ganham o estatuto de lei divina (COMISIÓN TEOLÓGICA INTERNACIONAL, 2006-20o8, n. 45). Mais ainda, a lei natural assume um caráter imutável, essencial, eterno, supra-histórico, que a faz permanente apesar das variações históricas, culturais, ideológicas. As regras que ela exprime são substancialmente válidas, "mesmo que alguém negue até os seus princípios, não é possível destruí-la nem arrancá-la do coração do homem. Sempre torna a ressurgir na vida dos indivíduos e das sociedades” (IGREJA CATÓLICA, 2011, p. 518).

O magistério da Igreja Católica postula a lei natural como preceito objetivo, universal e fundamental para a realização da pessoa humana; estará baseada na razão comum a todos os seres humanos, independente de suas convicções religiosas; deverá inspirar determinações morais, jurídicas e políticas; garantir a dignidade humana perante ideologias; e formula-se como o fundamento de colaboração entre todos os homens de boa vontade e inseparável do bem comum (COMISIÓN TEOLÓGICA INTERNACIONAL, 2006-2008, n. 9, n. 11). 
Assim, a lei divina e natural será utilizada para justificar a reinvindicação da Igreja como única autoridade com direito a afirmar a Verdade sobre o mundo e seu direito e dever de intervir quando necessário. Por isso, enquanto portadora de fundamentos mínimos para uma ética universal, a Igreja Católica sente-se na obrigação de evocar a lei natural em quatro contextos.

$\mathrm{O}$ primeiro, quando uma cultura limite a racionalidade à ciência mais rigorosa e abandona ao relativismo a vida moral. Aqui a Igreja insistirá na gramática ética inscrita no coração do ser humano que o faz capaz de reconhecer as normas fundamentais para um atuar justo de acordo com sua natureza e dignidade. O segundo, quando impere o individualismo relativista segundo o qual o indivíduo se constituí em fonte de seus próprios valores; então a Igreja lembra o caráter natural e objetivo que rege a vida política e social. "Os governos democráticos estão intrinsecamente vinculados a valores éticos estáveis cuja fonte é a lei natural, não dependendo de consensos flutuantes de maiorias aritméticas" (COMISIÓN TEOLÓGICA INTERNACIONAL, 2006-2008, n. 35). O terceiro contexto, se refere ao um laicismo agressivo que exclui do debate público os crentes. A Igreja insiste nas intervenções dos cristãos na vida pública sobre temas vinculados à lei natural, entre eles a defesa da vida e da família, liberdade religiosa e liberdade de educação. Direitos não de natureza confessional, mas cidadãos que têm a ver com bem comum da sociedade. Finalmente, a Igreja esgrime a defesa da lei natural perante totalitarismos, certas ideologias e abuso de poder; diante disso a Igreja sugere desobediência civil e liberdade de consciência quando as estruturas sociais esquecem o bem comum (COMISIÓN TEOLÓGICA INTERNACIONAL, 20062008, n. 35).

Há uma longa história que mostra como os conteúdos da lei natural foram sendo negociados, de acordo aos posicionamentos teológicos e políticos da Igreja, até se afirmar como doutrina e lhe outorgar um papel determinante na exposição da moral cristã. Dada a complexidade do tema, não cabe aqui discorrer sobre esse percurso, seja por sua densidade filosófica seja pelos meandros teológicos que o envolvem. Entretanto, para o propósito deste texto destacam-se alguns elementos 
que ilustrem a historicidade dos conceitos que formam parte do arsenal do magistério católico, compreendido esse como o ofício de interpretar autenticamente pelos bispos a Palavra de Deus7.

Na Idade Média, com os teólogos e juristas escolásticos, a lei natural alcança sua maturidade, torna-se referência e critério para legitimar as leis positivas e dos costumes particulares e emoldura-se num marco metafísico. Ao mesmo tempo, a escolástica, - entendida como o saber teológico-filosófico cristão com problems e métodos próprios, cultivado nas escolas medievales, também tido como o magistério eclesiástico, adquire uma preponderância ao deter a interpretação única e o controle rigoroso das verdades divinas reveladas, o que o leva a se erigir como guardião do depósito da fé.

O mundo moderno inverterá a relação fé e razão, essa última passará a comandar a ciência e a primeira será relegada a uma opção pessoal, também compreendida como privatização religiosa. Os processos de secularização colocaram em crise a ordem imutável e eterna, linguagem de um cristianismo universal. Com isso, o magistério será obrigado a justificar suas posições perante questões morais particulares e a explicitar a noção de lei natural. É o caso da moralidade sexual, que na lei natural aparecerá como um critério decisivo nas relações conjugais. Assim, na encíclica Arcanum divinae (1880), de Leão XIII, o matrimônio é reivindicado como competência exclusiva da Igreja. Já em Pio XI, na encíclica Casti connubii (1930) e em Paulo VI, Humanae vitae (1968), firma-se seu caráter monogâmico, indissolúvel, procriativo e heteronormativo (COMISIÓN TEOLÓGICA INTERNACIONAL, 2006-2008, n. 26-35).

De outro lado, também no século XIX, a origem divina da lei natural foi invocada para legitimar a Igreja, na sua pretensão de submeter os governantes a seu comando sacro. A lei divina, como verdade sobrenatural, cumpria a função específica de dominação da política mediante o controle moral da sociedade.

\footnotetext{
${ }^{7}$ A Comissão Teológica Internacional, aqui citada, se debruça sobre essa trajetória, fazendo referência a uma ampla documentação do magistério da Igreja, que sustenta sua argumentação.
} 
Já no século XX, a lei natural desloca-se de revelação divina para expressão de ordem sagrada em si mesma. Não é mais possível sacralizar a lei, por meio da lei divina, então fica apenas a lei natural. É nesse deslocamento que, para o sociólogo italiano Pino Tombretta (2015, p. 77), os processos fisiológicos e biológicos adquirem um caráter de valores inegociáveis, pois a natureza é em si mesma sacra. As relações sexuais e as diferenças entre sexos serão tidos como parâmetros sagrados. Segundo o autor, para o magistério da Igreja, será necessário fazer convergir as leis naturais e as verdades da fé com a razão. O caminho é entender que a natureza e razão são humanas, ambas isentas de crenças (TOMBRETTA, 2015, p. 77).

A partir daí, o próximo passo será apelar para a dignidade humana como valor sagrado. Natureza, razão e dignidade convergem para princípios inegociáveis. Processo que leva a uma secularização da própria doutrina. Não é necessário acreditar, mas há de se submeter às leis da natureza. A lei natural adquire uma nova fonte de legitimação, na qual valores e proibições interditam a natureza humana a partir da razão humana. Com isso, a lei natural passa a ter uma função ideológica: a de sacralizar a ordem social.

Porém, quando os estilos de vida modernos se recusam submeter a natureza humana aos desígnios de Deus instala-se a colisão entre a subjetividade moderna e os preceitos da Igreja. Ao constatar que novas relações societais deslocaram a finalidade reprodutiva da sexualidade para submetê-la à cultura da sensualidade e de culto ao corpo, uma nova frente moral se abre, interpelando a doutrina da lei natural. Diante disso, a sacralização dessa ordem social, cunhada na finalidade reprodutiva da sexualidade, fica insustentável.

Decorre disso que, o capital doutrinal que constitui a lei natural, alicerçada na sacralidade da natureza humana, será acionado pelo magistério da Igreja, outorgando-se o direito a dizer a verdade - em nome da liberdade religiosa. É bom lembrar que a doutrina enquanto instrumento cognitivo e moral dota os fiéis de capacidade para interpretar o mundo, adquirindouma função moral e social 
legitimadora da própria instituição. Ao mesmo tempo, como qualquer discurso religioso -aquele que fala a voz de Deus ou de qualquer representante dele - fixa relação desnivelada, de quem ouve e de quem fala; portanto, reflete a relação hierárquica entre o mundo temporal e espiritual. Interpretar e legitimar subjazem à estratégia de manter a hegemonia eclesiástica, ultrapassando os espaços institucionais, ao invocar sua origem divina, consequentemente, sua imutabilidade (porque revelada por Deus) e a pretensão de ser a totalidade social (TROMBETTA, 2015, p. 75).

Mas, a sociedade contemporânea não é a mesma que a medieval, como também não é a escolástica. Tanto hoje como outrora a produção doutrinal e seus idealizadores registram conflitos e tensões. De um lado, o mundo opõe resistência jurídica e societária perante uma instituição com pretensas tentativas de se erigir em totalidade social. Assim, o magistéiro da Igreja perde sua capacidade de impor como única verdade a doutrina que prega. Do outro lado, internamente o magistério não é um bloco mononolítico por conta das diversas posições teológicas que nem sempre convergem numa única direção. Evidentemente que essa dupla dimensão da doutrina, conflito e tensão, permeiam o jogo de xadrez em que se constitui negociar a lei natural numa sociedade plural.

Apesar disso, tensão-conflito, ou melhor, por conta disso, nas últimas décadas observa-se que, na esteira de negociações eclesiásticas, clérigos e leigos conservadores somam suas vozes a outros segmentos cristãos e não cristãos para, unidos, conclamar-se salvaguarda dos valores autênticos do cristianismo. Setores que vêm no gênero uma ameaça que atenta contra a criação e seu Criador, que, segundo eles, encontra nos regimes democráticos a brecha para deturpar os valores inegociáveis postulados pela lei natural. Invocar os valores morais, constitutivos da lei natural, porque constituem a base da ordem social e política, adquire relevância política quando se torna em mandato de defesa da natureza humana, como definda pela Igreja. Isso porque, a Igreja enquanto autodenominada "experta em humanidade" e portadora da Verdade terá o dever de intervir em contextos que ameaçem essa natureza, como já se mencionou. 
Consequentemente, em matéria de moralidade sexual, na percepção da Igreja Católica, os estudos de gênero configuram-se para a humanidade numa ameaça, num atentado à lei natural; daí o dever de intervir de forma global, articulada e permanente que a autoriza a estimular manifestações concretas: as campanhas antigênero. Mas, essas campanhas trazem um léxico epistemológico compartilhado no qual a sexualidade adquire uma dimensão política com conotações diferentes, como se verá a seguir.

\section{Gênero e feminismos contra o Criador}

As Jornadas Mundiais da Juventude (JMJ) respondem a uma iniciativa sistemática de reativar a memória de pertencimento da juventude à Igreja Católica, atualizar temáticas doutrinais e assuntos que explicitam a proposta de universalizar as relações sociais numa perspectiva própria de compreender o cristianismo (MARIZ; CARRANZA, 2017, p. 74). Na sua XXXI edição, realizada em Cracóvia (2016), o Papa reuniu-se com os bispos do país ${ }^{8}$. Formatada num diálogo, a intervenção de Francisco foi estruturada em quatro perguntas dirigidas ao Papa por bispos poloneses. Os assuntos versaram em relação à crise de fé perante os estilos de vida contemporâneos; religiosidade popular, vida paroquial, justiça, desigualdades sociais e migrantes.

A quarta pergunta, formulada pelo bispo auxiliar de Koszalin-Kotobrzeg, D. Krzysztof Zadarko, solicita do Papa uma orientação de como lidar pastoralmente com o sentimento de invasão que provoca, na região europeia, a chegada massiva de refugiados. Francisco lembraria sua própria situação de filho de migrantes, as causas da migração (trabalho, guerra, corrupção); reconhece que é um problema mundial de exploração da criação e de exploração de pessoas; e sugere as atitudes evangélicas de acolhimento e oração. Curiosamente ele termina dizendo: "Estamos a viver um momento de aniquilação do homem como imagem de Deus" (FRANCISCO, 2016, p. 9). Prestes a encerrar a resposta o Papa introduz o seguinte:

\footnotetext{
${ }^{8}$ Intervenção também evocada por Sarah Brack e David Paternotte na sua introdução ao volume do Religion and Gender dedicado à Ideologia de Gênero, cujos autores serão referidos neste texto (BRACK; PATERNOTTE, 2016).
} 
E aqui gostaria de concluir com um aspeto concreto, porque por detrás dele estão as ideologias. Na Europa, nos Estados Unidos, na América Latina, na África, nalguns países da Ásia, existem verdadeiras colonizações ideológicas. E uma delas - digo-a claramente por «nome e apelido» - é o gender! Hoje às crianças - às crianças! -, na escola, ensinase isto: o sexo, cada um pode escolhê-lo. E porque ensinam isto? Porque os livros são os das pessoas e instituições que te dão dinheiro. São as colonizações ideológicas, apoiadas mesmo por países muito influentes. E isto é terrível (FRANCISCO, 2016, p. 9).

A quebra de discurso será admitida quando o próprio Francisco (2016, p. 9) disse: “mas tu, Cristovão, dir-me-ás: 'e isto que tem a ver com os migrantes?'. Trata-se de um pouco de contexto, sabes?”. Um contexto que certamente coloca a Igreja em situação de campanha que demanda trazer à tona, em qualquer latitude e circunstância, a temática com "nome e apelido: gender!" Mais ainda, o sexo e o gênero serão enquadrados teologicamente ao ser evocado um diálogo entre Francisco e Bento XVI, onde o papa emérito lhe disse:

“Santidade, esta é a época do pecado contra Deus Criador" [...]. Deus criou o homem e a mulher; Deus criou o mundo assim, assim e assim; e nós estamos a fazer o contrário. Deus deu-nos um estado "inculto" para que o fizéssemos tornar-se cultura; e depois, com esta cultura, fazemos as coisas que nos levam ao estado "inculto"! Devemos pensar naquilo que disse o Papa Bento: "É a época do pecado contra Deus Criador!" (FRANCISCO, 2016, p. 9).

O tom das respostas de Francisco vinha na ênfase da misericórdia, acolhida, engajamento pastoral, perante as necessidades da Igreja local. A inflexão se dará, segundo informa a breve incursão do pontífice por uma situação de contexto, que a própria intervenção sugere ser geopolítico, de conspiração internacional, em que interesses econômicos estariam atuando diretamente, por meio de instituições e pessoas, para estabelecer uma colonização ideológica. Colonização que teria como alvo a educação escolar das crianças na qual, por meio de livros didáticos financiados por esses organismos internacionais, seria ensinado que o sexo é uma escolha.

Tal contexto de ameaça ideológica que afeta diretamente um setor vulnerável da sociedade, as crianças, obriga a Igreja a reagir. Garantida pela lei natural, como visto páginas atrás, a Igreja enquanto única autoridade com direito a 
afirmar a verdade sobre o mundo, terá o dever de intervir para defender os princípios mínimos de uma ética universal, que ultrapassa fronteiras e credos, e assegura uma convivência social harmoniosa.

Diante da iminente colonização ideológica, comandada pelo gênero, há de garantir-se a defesa da dignidade humana, essa para um crente assentada nos pressupostos de uma natureza de criação divina: “Deus criou o homem e a mulher”. A natureza será sagrada, imutável, eterna, porque encontra sua transcendência assegurada numa teologia da criação na qual "Deus criou o mundo assim, assim, assim”. Porém, o gênero, exatamente os estudos de gênero, estaria invertendo essa ordem divina já que "nós estamos a fazer o contrário", consequentemente contribuindo para uma época de pecado que se coloca contra o Deus Criador.

Essa inversão se faz, segundo o papa Francisco por meio dos próprios elementos fornecidos pela cultura pois: "Deus deu-nos um estado «inculto» para que o fizéssemos tornar-se cultura; e depois, com esta cultura, fazemos as coisas que nos levam ao estado «inculto»!" De certa forma, no olhar pontifício, retoma-se um dos efeitos da secularização: As pessoas agem independentemente de Deus e suas leis divinas. Afastadas Dele tendem, por sua vez, a se afastar da natureza e agir contra ela, consequentemente, a cometer um pecado contra o Deus Criador.

Mas, na perspectiva da lei natural, se para o crente esse afastamento das leis naturais é pecado, para um não crente (isento de crenças) significa não realizar o mandato do bem moral que, enquanto ser humano leva inscrito como gramática no coração, portanto, pela razão que confere as condições de reconhecer e pela ética universal o dever de realizar. Crentes e não crentes, ao se afastarem os primeiros da lei divina e os segundos da lei natural, ambos estariam atentando contra sua própria natureza e dignidade humana, uns por razões de fé pecariam, e os outros pela recusa a fazer o bem moral que pelo uso da razão podem realizar (IGREJA CATÓLICA, 2011, p. 517). 
$\mathrm{Na}$ contramão, dessa argumentação na qual a natureza humana e sua dignidade são sustentadas em pressupostos ético-teológicos, encontram-se os pressupostos da categoria analítica gênero. Esses últimos, talvez,estão do lado do "estado inculto" ameaçante e ameaçador, mencionado pelo Papa. Dado que suas eseus estudiosos, munidos com as ferramentas das ciências sociais e em diálogo com a biologia e a medicina, constroem outro arsenal analítico, outros pressupostos epistemológicos sobre a compreensão da natureza humana e sua sexualidade. Esses propõem repensar as diferenças entre sexos como determinantes biológicos, estendendo sua mirada às evidências empíricas que apontam para a plasticidade da sexualidade. Sugerem a desmistificação dos imperativos de ser homem ou mulher, papéis sociais aprendidos e religiosamente sacralizados como lei da natureza. Questionam os pressupostos que submetem os seres humanos a uma inexorável lei da natureza, legitimando uma ordem social em que as relações entre os sexos são organizadas de maneira assimétrica no trabalho, na esfera doméstica e na política. Alertam para o poder da linguagem, discursiva e simbólica, como estruturadora de subjetividades e de identidades e sua função naturalizadora de conceitos, definições e preconceitos que trazem um impacto social (ROSADO-NUNES, 2018, p. 20).

E é aí que entra o Feminismo como movimento social que elabora um pensamento alternativo ao paradigma biomédico, naturalizador e hegemônico, a tempo que ganha relevância política e social. O feminismo será devedor dos ideais da modernidade. Como é sabido, a modernidade de alguma forma se "liberta" da religião e seus valores integram um ideário distante de uma cultura religiosa e que incluem: a autonomia das pessoas; a realização de si e os valores democráticos, esses últimos entendidos como um modo societário instaurado na cultura ocidental. Em uma longa e densa discussão sobre o processo de exculturação do Catolicismo, Hervieu-Léger (2003) entende que a "lógica democrática da afirmação igualitária dos indivíduos mina, em todos os domínios da vida social, e não apenas na ordem política, a construção hierárquica da autoridade "vinda do alto"” (HERVIEU-LÉGER, 2003, p. 213). Decorrente, a questão do sexo e da reprodução 
tem lugar central pois estende os valores democráticos para a sexualidade dando lugar, nos termos de Fassin (2016, p. 178), à democracia sexual.

A regulação do que se pode ou não fazer nessas duas áreas da vida, sexo e reprodução, afasta-se da moral prescrita pelas religiões. O Feminismo desloca a sexualidade para o campo dos direitos, dos reclamos por cidadania, por uma democracia sexual. Cria uma linguagem política para tratar questões relativas à reprodução e ao sexo, colocando na pauta política: direitos sexuais e direitos reprodutivos (BIROLI, 2013, p. 83). Tal deslocamento opera uma verdadeira mudança paradigmática do pensamento sobre a sexualidade e seus comportamentos .

Até o exposto aqui, não é necessário insistir em que os estudos de gênero e a doutrina da lei natural partem de pressupostos epistemológicos diferentes e não complementares ao discutirem a natureza humana e sua sexualidade. Para os primeiros serão categorias construídas histórica e socialmente, enquanto para os segundos noções evidentes, dadas, sagradas e sacralizadas. Por trás dessa controvérsia encontra-se uma outra: o problema dosuniversais, fortemente discutida na Idade Média que trata, grosso modo, sobre que tipo de realidade se deve conceder às ideias gerais ou universais9. Elas são reais, como sugeria Platão (realismo), ou simples palavras (nomalismo)?

Embora essa questão filosófica pareça remota, sua importância reside em que discute se a realidade das ideias é reconhecida ou nomeada. Os nominalistas consideram que as ideias não têm outra realidade além das palavras que servem para as designar - só os indivíduos existem e as generalidades (universais) apenas pela linguagem. Já os realistas afirmam a existência de uma realidade independente do espírito humano - o realismo tende a ser invocado num sentido mais geral ou metafísico. No ato de cognição, realistas observam, percebem e

\footnotetext{
${ }^{9}$ Outra explicação descreve o problema dos universais como um conjunto historicamente variável de vários quadros proximamente relacionados, mas em diferentes quadros conceituais, articulados de forma metafísica, lógica e epistemológica, em última instância todos ligados à questão de como a cognição universal das coisas singulares é possível. Para mais detalhes, consultar: Stanford Encyclopedia of Philosophy (2010).
} 
nomeiam uma ordem real do universo e para nominalistas nomear, classificar, categorizar é apenas um ato de criação e/ou invenção. Dito de outra forma, existem categorias porque os seres humanos reconhecem distinções no mundo em torno deles, ou são as categorias convenções arbitrárias ou simplesmente os nomes dados para coisas têm força categórica porque os seres humanos concordam em usá-los de determinadas maneiras? Entretanto, como já se disse acima, nomear, categorizar, classificar, definir como operações discursivas abreviam opiniões teóricas e condensam processos históricos, também, não estão isentas de tensão e tem suas consequências práticas e impacto político.

Em matéria de gênero e sexualidade continuam latentes as controvérsias entre nominalistas e realistas. Fassin (2016) as revisita sugerindo que "a católica naturalização da diferença sexual dentro do casamento confirma claramente a natureza essencialista do argumento contra a construção social de gênero" (FASSIN, 2016, p. 181). Por sua vez, o núcleo central dos estudos de gênero é que o elemento constitutivo das relações sociais baseadas na percepção das diferença entre os sexos, sendo gênero uma forma primordial de significar relações de poder (FASSIN, 2016, p. 184).

Na trilha do autor, enquanto os estudos de gênero e o feminismo certamente podem ser caracterizados como nominalistas (construcionistas sociais, no debate atual) ${ }^{10}$, os representantes e/ou adeptos da doutrina católica como realistas ou essencialistas - esses últimos na compreensão de que a essência precede a existência ou que um ser está contido na sua definição. De tal forma que, quando se trata da compreensão da natureza humana, como discutido acima, existe uma verdadeira oposição entre essencialistas e construccionistas sociais e são seus pressupostos epistemológicos, como um léxico epistemológico, que subjazem hoje à polêmica do gênero.

\footnotetext{
${ }^{10}$ De maneira sucinta pode-se dizer que, na atualização do mapa conceitual o construcionismo social, discussão oriunda da Psicologia, procura sublinhar a especificidade cultural e histórica das formas de conhecimento, dando primazia aos relacionamentos humanos nessa produção. A proposta construccionista valoriza uma postura crítica e reflexiva, a interligação entre conhecimento e ação, a prática científica que incida culturalmente e amplie vocabulários relacionais. Para mais detalhes, ver: Rasera; Japur (2005, p. 21).
} 
As percepções mútuas sobre o impacto que a compreensão da sexualidade e sua moral tenham se condensam, de um lado, em que os essencialistas religiosos (realistas) veem nos construccionistas sociais do gênero (nominalistas) um perigo ideológico de subversão dos valores humanos tidos como absolutos universais. De outro lado, os construccionistas veem nos essencialistas um campo conservador, quando não reacionário, pelo reconhecimento implícito do valor e imutabilidade do status quo (FASSIN, 2016, p. 184). Porém, essa não é apenas discussão de postulados, acadêmicos e doutrinais, restrita aos muros da especulação, mas uma batalha política: onde os pressupostos do feminismo têm a categoria de gênero, e os valores inegociáveis da moralidade cristã (e sexual), a lei natural.

Ao serem desconstruídas pelos estudos de gênero categorias há tanto tempo estabelecidas sobre bases binárias e essencialistas, também é uma determinada ordem e um regime de verdades, com aspiração a continuar a ser a totalidade social, que será colocada em questionamento. De certo, parafraseando HervieuLéger (2003), o fim de um mundo, o que não é forçosamente o fim do mundo, será iminente, porque a natureza não é mais uma ordem.

Polêmica epistemológica que tem-se deslizado para a esfera social onde os estudos de gênero adquiriram sua relevância política, quer seja quando seu léxico epistemológico é apropriado pelo movimento feminista, quer quando tornou-se alvo de campanhas sistemáticas de desqualificação e acusação por parte de grupos religiosos. Ambos os lados compartilham da mesma dimensão política da sexualidade e do gênero, os segundos acusando o gênero de ser politização do sexo, enquanto seu contra-ataque não é menos político (FASSIN, 2016, p. 184).

Por isso, é na arena política que os pressupostos epistemológicos da doutrina católica adquirem tons antigênero, confluindo numa batalha expressa em campanhas internacionais. Essas se consolidam como trincheiras defensivas contra os pressupostos teóricos de gênero ao firmar narrativas da ordem social baseadas na lei natural, estendendo-se, como se verá nas próximas considerações finais, como argumentos legítimos para incluir, alterar ou suprimir iniciativas que afetam a esfera de direitos, extamente na contramão do ativismo feminista. 


\section{Considerações finais: a força política do gênero}

Em maio de 2016, no tradicional almoço anual da National Catholic Prayer Breakfast, em Whasington ${ }^{11}$, o Cardeal africano Robert Sarah sublinhou que a defesa da família é uma tarefa fundamental nas sociedade atual. O Prefeito da Congregação para o Culto Divino e a Disciplina de Sacramentos do Vaticano afirma: “[...] não é uma guerra ideológica. Trata-se na verdade de defender-nos a nós mesmos, os nossos filhos e as gerações futuras ante uma ideologia demoníaca (a ideologia de gênero), a qual afirma que as crianças não necessitam mães e pais. Ela nega a natureza humana e quer extirpar Deus de gerações inteiras” (SARAH, 2016). Um ano antes, em entrevista ao jornal francês Dimanche, Sarah (2015) declarava estar empenhado pessoalmente "contra a chantagem das Nações Unidas" que, segundo ele, "querem impor o culto à ideologia de gênero aos países africanos em troca de ajuda ao desenvolvimento". Na visão do prelado, "não é atacando a família que se protege a sociedade. Eu diria que é o contrário [...]. Eu acho que, como cristão, é hora de colocar Deus no centro da sociedade”.

Rente à preocupação do Papa Francisco e de Bento XVI, de estar ameaçada a humanidade por uma ideologia que destrói a pessoa, a família e as novas gerações, o Cardeal Sarah retoma não apenas o viés conspiratório que a campanha antigênero do Vaticano tem assumido, mas também os pressupostos doutrinais da transcendência da natureza humana e da necessidade de trazer o regime de verdades como epicentro das relações sociais. Regime ancorado na lei natural que, com concepções binárias e essencialistas, para seus defensores constitui-se numa determinada ordem com aspiração a ser a totalidade social.

Tal campanha, assumida pessoalmente por Sarah, revela o perigo que traz a categoria gênero, quando questiona os pressuposto dessa ordem tida como natural, e o feminismo com seu engajamento político. Para Mary Anne Case (2018, p. 42) as preocupações do Vaticano vão além de acusações de militantes feministas e

\footnotetext{
${ }^{11}$ Estabelecido em 2004 em resposta ao chamado do Papa João Paulo II para uma nova evangelização, o Café da Manhã Nacional de Oração Católica reúne em torno de 1.500 pessoas. Tido como suprapartidário atraí palestrantes leigos e religiosos para pregar e rezar pela nação norte-americana.
} 
defensores de direitos sexuais, pois a agenda de gênero tem conexões mais amplas do que sexo e gênero. A preocupação da Igreja Católica, segundo a autora, é reivindicar publicamente seu direito e sua responsabilidade de proteger a criação e o ser humano da autodestruição. Para isso, a Igreja se engaja politicamente promovendo e liderando suas próprias campanhas (CASE, 2018, p. 42).

Mas o investimento contra o gênero é mais complexo e não é um empenho só da Igreja Católica. Ele está presente, como alerta Sara Bracke e David Paternotte (2016, p. 146-147) ${ }^{12}$, em outras tradições religiosas, grupos políticos conservadores, ainda que a Igreja desempenhe um protagonismo essencial com a invenção do conceito "ideologia de gênero", enquanto uma forma particular de resistência que traz suas amarras intelectuais e teológicas. Entretanto, para os autores, os sentimentos antigênero respondem a uma crítica cultural que transcende a religiosa e tem repercussões políticas na sociedade.

Isso pode ser ilustrado, a título de exemplo, em alguns acontecimentos dos últimos cinco anos em países da América Latina. Assim, no contexto da Reforma Constitucional do Distrito Federal do México, circulou um ônibus “antigênero” por todo o país e pela Região chegando até o Chile; no Equador uma lei de violência de gênero foi atacada violentamente por grupos conservadores; a Corte Constitucional Boliviana derrogou uma lei, recentemente aprovada, de identidade de gênero, argumentando que a dignidade da pessoa humana tem sua raiz no sexo binário; nas eleições de Colômbia, Costa Rica e Brasil uma das bandeiras eleitorais foi a ideologia de gênero; finalmente, em torno da reforma do sistema de Educação no Uruguai uma outra campanha antigênero foi deflagrada (CÔRREA; D’ELIO, 2018, p. 7). Não muito longe dessa incursão antigênero, o Plano Nacional de Educação (PNE - 2014-2024) que abrangia questões de gênero e o Projeto de Lei 122/2006, que instituía a criminalização da homofobia, desencadeou no Congresso brasileiro

\footnotetext{
${ }^{12}$ A densidade e abundante literatura sobre a ideologia de gênero, e o propósito de nosso texto, não nos autoriza adentrarmos no termo, apenas o registramos como uma categoria acusatória que desqualifica e que permite demonizar processos analíticos complexos. Mais ainda, a noção ideologia de gênero é amplamente questionável por operar com noções de gênero que não refletem a longa trajetória intelectual do conceito. Para maiores aprofundamentos, ver: Facchini; Sívori (2017).
} 
uma tormenta jurídico-política, aglutinando grupos conservadores e religiosos contra movimentos sociais e feministas (CARRANZA; CUNHA, 2018; MACHADO, 2018).

A serventia política que o gênero presta a essas campanhas está em reunir, no topo da agenda de ativistas católicos e conservadores, uma gama de preocupações que oscilam desde os direitos reprodutivos das mulheres até o apego a papéis específicos para homens e mulheres e a transgressão de normas sobre sexualidade (BRACKE, PATERNOTTE, 2016, p. 148). Gênero como conceito fornece as conexões analíticas e políticas entre esses diferentes tópicos, tornando as diversas questões numa visão coerente. Ao mesmo tempo, gênero amalgama atores sociais dissidentes (feministas, ativistas LGBTQ+, estudiosos de gênero) sob uma única figura, num inimigo a ser combatido, principalmente pela Igreja Católica. Pavimentada a demonização do gênero e diante da sua fase de extremos diabólicos, a Igreja com a razão e a lei natural se posiciona em defesa do divino.

Em que pese uma evidente constatação de que as campanhas antigênero parecem representar o retorno a um catolicismo tradicional ou retrógrado, argumenta-se aqui que são muito mais do que isso. De um lado, elas condensam o corpo doutrinal que negocia mínimos éticos universais, organiza uma desordem moral, consolida o senso comum pautado por visões binárias do gênero e da sexualidade, conecta com aspirações sociais de estabilidade, canaliza e dá coerência interna a discursos de perversão e anormalidade. Do outro lado, levam a opinião pública a se alertar sobre um debate que, até então, estaria nos bastidores acadêmicos, com reverberação nas lutas dos movimentos feministas e LGBTQ+. Seja essa, talvez, a força que atrai setores não religiosos para engrossar as campanhas antigênero e fazer do feminismo um de seus inimigos. Por parte das campanhas antigênero dos religiosos os estudos de gênero são reduzidos a uma nociva doutrina política que revoga a ordem social tal como inscrita nas leis divinas e nas leis da natureza. 
Tende-se, então, a concordar com Joan Scott (2018, p. 83), quando salienta que as manifestações antigênero trazem em si certa reversão do objeto rejeitado. Isso porque, ao se apropriar da noção de gênero, mesmo que de forma equivocada, e reverberar seu potencial político como ameaça, implicitamente as campanhas provam a inevitável mutabilidade do gênero e a impossibilidade de fixar os significados das diferenças do sexo de forma definitiva (SCOTT, 2018, p. 83). Diferenças que precisam de "roupa" para serem reconhecidas, como capturado no sketche das crianças que olhavam a gravura de Adão e Eva, descrita na introdução desta reflexão. Marcadores sociais que devem ser carregados de sentido religioso para legitimar a tarefa eclesiástica de intervir quando ameaçada a natureza humana e sua transcendência e de mostrar o caminho certo.

Mais ainda, a oposição sistemática ao gênero pela sua significação das relações de poder, só reafirma sua existência e relevância. Com isso, arrisca-se a pensar que, os ataques antigênero certamente estarão direcionados a atenuar os efeitos que esses questionamentos trazem ao poder estabelecido, mais do que à desestabilização que o gênero possa trazer à sexualidade e ao leque de prescrições normativas correlatas. Com isso, em se tratando de poder está-se falando de política, portanto, o que começa como pressupostos epistemológicos, objeto de especulação acadêmica e intelectual, adquire as dimensões que impulsionam o mundo da política.

Na sequência, os distintos pressupostos epistemológicos sobre a natureza humana que, tanto os estudos de gênero quanto o magistério da Igreja Católica sustentam, alicerçam uma poderosa retórica que na esfera política nutre os embates entre dois movimentos políticos: o feminista e as campanhas antigênero. Em sendo, na correlação de forças o primeiro mostra sua capacidade de desregrar o pensamento estabelecido e o segundo o seu poder articulador de resistência a esse desregramento. Mas, se no entramado jurídico e das políticas públicas fortes batalhas têm sido ganhas por ambos os movimentos, ainda é cedo para apostar quem vencerá essa guerra. Isso porque os ganhos reais no entramado civilizatório 
só o tempo poderá dizer. Por ora, a tensão entre recuar e avançar adquire traços mais elevados de beligerância nacional e internacional e como sempre o lado mais fraco da contenda tende a ser o mais vitimado.

\section{REFERÊNCIAS}

BIROLI, Flávia. Autonomia, opressão e identidades: a ressignificação da experiência a ressignificação da experiência na teoria política feminista na teoria política feminista. Estudos Feministas, Florianópolis, v. 21, n. 1, p. 81-105, jan.-abr. 2013.

BRACKE, Sarah; PATERNOTTE, David. Unpacking the sin of gender. Religion and Gender, v. 6, n. 2, p. 143-154, 2016.

BUTLER, Judith. Conferencia de Judith Butler en la UNTREF (Transcripción completa). 2015a. Disponível em: http://www.ramona.org.ar/node/57395. Acesso em: 4 dez. 2018.

BUTLER, Judith. Corpos que importam. Tradução de Magda Guadalupe dos Santos e Sérgio Murilo Rodrigues. Sapere Aude, Belo Horizonte, v. 6, n. 11, p. 12-16, $1^{\circ} \mathrm{sem}$. 2015b.

BUTLER, Samuel. The note-books of Samuel Butler. Edited by Henri F. Jones. New York: E. P. Dutton \& CO, 1917. Metadata original scanning. Disponível em: https://archive.org/details/cu31924013448299. Acesso em: 4 dez. 2018.

CARRANZA, Brenda; CUNHA, Christina Vital da. Conservative religious activism in the Brazilian Congress: sexual agendas in focus. Social Compass, v. 65, n. 4, p. 486-502, 2018. DOI: 10.1177/0037768618792810. Disponível em: http://journals.sagepub.com/doi/pdf/10.1177/o037768618792810. Acesso em: 20 maio 2019.

CASE, Mary Anne. El rol de los Papas en la invención de la complementariedad y la anaematización del género desde el Vaticano. In: BRACKE, Sara; PATERNOTTE, David (ed.). Habemus género, la Iglesia Católica e ideología de género: textos seleccionados. Rio de Janeiro: Asociación Brasilera Interdisciplinar de SIDA: Observatorio de Sexualidad y Política, 2018. p. 26-56. Disponível em: http://www.sxpolitics.org. Acesso em: 20 maio 2019.

COMISIÓN TEOLÓGICA INTERNACIONAL. En busca de una ética universal: nueva perspectiva sobre la lay natural, oct. 2006-dez. 2008. Disponível em:

http://www.vatican.va/roman_curia/congregations/cfaith/cti_documents/rc_con_cfaith _doc_20090520_legge-naturale_sp.html. Acesso em: 30 nov. 2018.

CONNEL, Raewyn. Gênero em termos reais. Tradução de Marília Moschkovich. São Paulo: nVersos, 2016. 
CORREAA, Sonia; D’ELIO, Fernando. Prólogo. In: BRACKE, Sara; PATERNOTTE, David (ed.). Habemus género, la Iglesia Católica e ideología de género: textos seleccionados. Rio de Janeiro: Asociación Brasilera Interdisciplinar de SIDA: Observatorio de Sexualidad y Política, 2018. p. 4-7. Disponível em: http://www.sxpolitics.org. Acesso em: 18 maio 2019.

DUQUE, Tiago. Gêneros incríveis: um estudo sócio-antropológico sobre as experiências de (não) passar por homem e/ou mulher. Campo Grande, MS: Ed. UFMS, 2017.

FACCHINI, Regina; SÍVORI, Horacio. Conservadorismo, direitos, moralidades e violência: situando um conjunto de reflexões a partir da Antropologia. Cadernos Pagu, Campinas, n. 50, p. 1-18, 2017. Disponível em: http://dx.doi.org/10.1590/18094449201700500000. Acesso em 7 mar. 2019.

FASSIN, Éric. Gender and the problem of universals: catholic mobilizations and sexual democracy in France. Religion \& Gender, v. 6, n. 2, p. 173-186, 2016. DOI: https://10.18352/rg.10157.

FAUSTO-STERLING, Anne. Dualismos em duelo. Cadernos Pagu, Campinas, n. 17/18, p. 9-79, 2002. Disponível em: http://www.scielo.br/pdf/cpa/n17-18/n17a02. Acesso em: 21 maio 2019.

FRANCISCO, Papa. Viagem Apóstolica do Papa Francisco à Polónia por ocasião da XXXI Jornada Mundial da Juventude (27-31 de Julho de 2016). Encontro com os Bispos polacos. Diálogo. Catedral do Wawel, Cracóvia, quarta-feira, 27 de julho de 2016. Disponível em: http://w2.vatican.va/content/francesco/pt/speeches/2016/july/documents/papafrancesco_20160727_polonia-vescovi.html. Acesso em: 15 maio 2019.

GARDEY, Delphine; LÖWY, Ilana. L'Invention du naturel: les sciences et la fabrication du féminin et du masculin. Paris: Éditions des Archives Contemporaines, 2000.

HARAWAY, Donna. Saberes localizados: a questão da ciência para o feminismo e o privilégio da perspectiva parcial. Cadernos Pagu, Campinas, n. 5, p. 7-41, 1995.

HARDING, Sandra. A instabilidade das categorias analíticas na teoria feminista. Revista Estudos Feministas, v. 1, n. 1, p. 7-32, 1993.

HEILBORN, Maria Luiza. Fronteiras simbólicas: gênero, corpo e sexualidade. Cadernos Cepia, Rio de Janeiro, n. 5, p. 73-92, , dez. 2002.

HERVIEU-LÉGER, Daniéle. Catholicisme, la fin d'un monde. Paris: Bayard, 2003.

IGREJA CATÓLICA. Papa (1878-1903: Leão XIII). Sobre a liberdade humana: Libertas Praestantissimum. Petrópolis: Vozes, 1946.

IGREJA CATÓLICA. Papa (1978-2005: João Paulo II). Catecismo da Igreja Católica. São Paulo: Edições Loyola, 2011.

LAQUEUR, Thomas W. Making sex: body and gender from the greeks to Freud. Cambridge: Harvard University Press, 1990. 
MACHADO, Maria das Dores Campos. O discurso cristão sobre a "ideologia de gênero". Revista de Estudos Femininos, Florianópolis, v. 26, n. 2, p. 1-18, 2018. https://doi.org/10.1590/1806-9584-2018v26n247463 . Disponível em: http://www.scielo.br/pdf/ref/v26n2/1806-9584-ref-26-02-e47463.pdf. Acesso em: 02 fev. 2019.

MARIZ, Cecília; CARRANZA, Brenda. Francisco en la Jornada de la Juventud de Rio de Janeiro. In: FRIGERIO, Alejandro; ROLDÁN, Verónica (ed.). Francisco: el impacto de su pontificado en América Latina. Buenos Aires: Editorial Biblos, 2017. p.71-88.

RASERA, Emerson Fernando; JAPUR, Marisa. Os sentidos da construção social: o convite construccionista para a Psicologia. Paidéia, v. 15, n. 30, p. 21-29, 2005.

ROSADO-NUNES, Maria José. Quando a natureza não é mais uma ordem: os desafios do feminismo à religião. In: GOMES, Ana Maria; REIS, Aparecido Francisco dos; VEIGA, Vivian da (org.). Diálogos sobre gênero e sexualidade. Campo Grande: Life Editora, 2018. p. 11-25.

SARAH, Robert. Cardeal Sarah: ideologia de gênero é mortal e demoníaca. [Entrevista cedida a] Sabrina Fusco. ACI Digital, Lima, 19 maio 2016. Disponível em: https://www.acidigital.com/noticias/cardeal-sarah-ideologia-de-genero-e-mortal-edemoniaca-10970. Acesso em: 2 fev. 2019.

SARAH, Robert. Cardinal Robert Sarah: Porquoi l'Église devrait-elle changer? [Entrevista cedida a] Marie-Christine Tabet. Le Journal du Dimanche, Paris, 8 mars 2015 [modifié le 20 juin. 2017]. Disponível em: http://www.lejdd.fr/Societe/Religion/Cardinal-RobertSarah-Pourquoi-l-Eglise-devrait-elle-changer-721682. Acesso em: 7 mar. 2019.

SCOTT, Joan. El género y el Vaticano. In: BRACKE, Sara; PATERNOTTE, David (ed.). Habemus género, la Iglesia Católica e ideología de género: textos seleccionados. Rio de Janeiro: Asociación Brasilera Interdisciplinar de SIDA: Observatorio de Sexualidad y Política, 2018. p. 81-83. Disponível em:< http://www.sxpolitics.org >. Acesso em: 20 maio 2019.

STANFORD ENCYCLOPEDIA OF PHILOSOPHY. The Medieval Problem of Universals. First published Sun Sep. 10, 2000; substantive revision Tue Oct. 31, 2017. Disponível em: https://plato.stanford.edu/entries/universals-medieval/. Acesso em: 20 maio 2019.

TOURAINE, Alan. O mundo das mulheres. Petrópolis: Vozes, 2010.

TROMBETTA, Pino Lucà. Oltre i valori non negoziabili? Francesco e la crisi della dottrina della legge naturale. Religioni e Societá, anno 30, n. 81, p. 75-80, genn.-apr. 2015. DOI: $10.1400 / 232168$.

VAGGIONE, Juan Marco. Introducción. In: FAÚNDES, José Manuel Morán et al (ed.). Sexualidades, desigualdades y derechos: reflexiones en torno a los derechos sexualesy reproductivos. Córdoba: Ciencia, Derecho y Sociedad Editorial, 2012. p. 13-55.

WOODHEAD, Linda. Gender differences in religious practice and significance. International Advances in Engineering and Technology (IAET), v. 13, p. 58-85, Jan. 2013. 